\title{
PROPAGATION AND RUNUP OF TSUNAMI WAVES WITH BOUSSINESQ MODEL
}

\begin{abstract}
Xi Zhao ${ }^{1}$, Benlong Wang ${ }^{2}$, Hua Liu $^{3}$
With certain profiles of bottom movements, orders of wave height of submarine earthquake-induced tsunami both in deep ocean and nearshore area have been studied using the Boussinesq equations. An earthquake of large magnitude generates a typical $\mathrm{N}$-wave which can propagate long distance in open ocean without deformation. Since the magnitude and length of tsunami waves related to vertical and horizontal scale of geological movements, solitary wave and $\mathrm{N}$-wave are extended to waves not tied to solitary property which represent tsunami waves better. In a horizontal one dimensional numerical wave flume, runup of solitary wave, $\mathrm{N}$-wave, single crest and $\mathrm{N}$-wave composed by a single crest and a single trough on a slope beach have been simulated. The results fit analytical solutions of nonlinear shallow water equations well. The Indian Ocean tsunami has been simulated with the horizontal two dimensional high order Boussinesq model. Comparison between numerical results and measured data from field survey validates the numerical model.
\end{abstract}

Keywords: tsunami waves, $N$-wave, runup, Boussinesq equations

\section{INTRODUCTIONS}

Most submarine earthquakes generate tsunamis as a type of $\mathrm{N}$-wave. Analytical and numerical models are always consistent with the reports of tsunamis that the shoreline first recede and then advance up the beach, e.g. Tadepalli and Synolakis (1994). It indicates that the classical solitary theory may be inappropriate to model certain of the tsunami events. Tadepalli and Synolakis (1994) introduced the concept of $\mathrm{N}$-wave and gave the definition of a class of $\mathrm{N}$-waves. Leading-depression $\mathrm{N}$-wave (LDN) may be considered as a solitary wave with a depression trough in front which alters the property of solitary wave. Based on shallow water equations (SWE), they derived certain asymptotic results for maximum runup of $\mathrm{N}$-waves.

Like solitary wave, the profile of N-wave proposed by Tadepalli and Synolakis (1994) is defined by the water depth $h$ and non-dimensional wave height $H / h$. Generally initial surface displacement induced by submarine earthquake highly related to the seismic activity. Madsen and Schäffer (2010) presented several waveforms not tied to solitary wave theory which are appropriate for simulating real tsunami waves. They extended the work of solitary wave and N-wave studied by Synolakis (1987) and Tadepalli and Synolakis (1994) to single wave and $\mathrm{N}$-wave composed by superposition of positive and negative single waves. Furthermore, the rundown phase are provided analytically in Madsen and Schäffer (2010) in the framework of nonlinear shallow water equations (NSWE).

Initial displacement of the free surface induced by earthquakes of large magnitude are the $\mathrm{N}$-waves with long wave length and small amplitude. For these kind of waves, dispersion may be important because the dispersive number $k h$ is of the order between $O\left(10^{-2}\right) \sim\left(10^{-1}\right)$. For the Indian Ocean tsunami, the dispersion parameter $k h$ is estimated as $0.026 \leq k h \leq 0.25$, see Lay et al. (2005) and Zhao, Wang and Liu (2009). For linear problem, the free surface disturbance induced by seabed movements can be analytically solved using potential theory with the linearized boundary conditions, e.g. Hammack (1973), Todorovska and Trifunac (2001) using Fourier-Laplace transform and Zhao, Wang and Liu (2009) using power series solution of Laplace equations. For practical applications, linear KdV equation and the Boussinesq equations are suitable for modelling wave propagation in open ocean. When waves propagate to the near shore area and runup on the beach, nonlinearity plays an important role. NSWE and the Boussinesq equations are suitable for modelling wave dynamics in swash zone. It is supposed that the Boussinesq equations can be used to study the generation, propagation and runup of tsunami waves.

As analyzed by Madsen, Bingham and Liu (2002), the Boussinesq model has excellent both the linear and nonlinear properties, such as linear dispersion, shoaling, subharmonics and superharmonics transmission. Zhao, Wang and Liu (2009) extended the Boussinesq model to include the effects of the temporal varying bottom and discussed the accuracy of the transfer function between the temporal varying bottom and the response of the free surface. In the present work, the enhanced Boussinesq model for fully nonlinear highly dispersive waves is extended to establish a numerical model of the generation, propagation and runup of tsunamis induced by submarine earthquakes.

\footnotetext{
${ }^{1}$ xzhao_2000@sjtu.edu.cn, Department of Engineering Mechanics, Shanghai Jiao Tong University, Shanghai, China

${ }^{2}$ benlongwang@sjtu.edu.cn, Department of Engineering Mechanics, Shanghai Jiao Tong University, Shanghai, China

${ }^{3}$ hliu@sjtu.edu.cn, Department of Engineering Mechanics, Shanghai Jiao Tong University, Shanghai, China
} 
In this paper, the high order Boussinesq model is described in Section 2. The whole life span of tsunami waves from its generation, propagation and runup on a beach is studied in horizontal one dimensional model. The simplified earthquake model is established, and waveforms for the cases of different magnitude of earthquakes are presented in Section 3. Tsunami waves propagating on constant depth and shoaling on a gentle slope are computed in Section 4. In Section 5, the runup of solitary wave and $\mathrm{N}$-wave with solitary property which means wave profile determined by the water depth $h$ and non-dimensional wave height $H / h$, single crest and double single waves not tied by solitary property are studied. In Section 6, verifications of a two dimensional Boussinesq model are carried out by wave runup on a conical island. In Section 7, the Indian Ocean tsunami is simulated with the two dimensional Boussinesq model. Simulation results will be compared with field measured data. Summary and conclusions are given in Section 8.

\section{THE GOVERNING EQUATIONS}

Assuming the fluid is incompressible and the flow is irrotational, the kinematic boundary condition and dynamic boundary condition at the free surface are (Zakharov 1968, Witting 1984, Wu 2001)

$$
\begin{gathered}
\frac{\partial \zeta}{\partial t}-\tilde{w}+(\tilde{\mathbf{V}}-\tilde{w} \nabla \zeta) \cdot \nabla \zeta=0 \\
\frac{\partial \tilde{\mathbf{V}}}{\partial t}+g \nabla \zeta+\frac{1}{2} \nabla\left[\tilde{\mathbf{V}} \cdot \tilde{\mathbf{V}}-\tilde{w}^{2}(1+\nabla \zeta \cdot \nabla \zeta)\right]=0
\end{gathered}
$$

where

$$
\tilde{\mathbf{V}} \equiv \nabla \phi(x, y, \zeta(x, y, t), t)=\tilde{\mathbf{u}}+\tilde{w} \nabla \zeta
$$

Here $\zeta$ is the surface elevation, $t$ is time, $g$ is the acceleration of gravity, $\nabla=(\partial / \partial x, \partial / \partial y, 0)$ is horizontal gradient operator.

The kinematic bottom boundary condition can be formulated as

$$
w_{b}+\mathbf{u}_{b} \cdot \nabla h=-h_{t}
$$

where $\mathbf{u}_{b}$ is the horizontal velocity vector and $w_{b}$ is the vertical velocity component evaluated on the bottom. $\tilde{\mathbf{u}}$ is the horizontal velocity vector and $\tilde{w}$ is the vertical velocity component defined on the free surface. The right-hand term in Eq. 4 represents the temporal varying bottom.

The flow field can be expressed as

$$
\begin{aligned}
& \mathbf{u}(x, y, z ; t)=\cos ((z-\hat{z}) \nabla) \hat{\mathbf{u}}+\sin ((z-\hat{z}) \nabla) \hat{w} \\
& w(x, y, z ; t)=\cos ((z-\hat{z}) \nabla) \hat{w}-\sin ((z-\hat{z}) \nabla) \hat{\mathbf{u}}
\end{aligned}
$$

$\hat{\mathbf{u}}$ and $\hat{w}$ are the velocity components taken at an arbitrary level $z=\hat{z}$. Eqs. 1-4 and 5a-5b compose the high order Boussinesq wave model. The infinite Taylor series operators are defined by

$$
\begin{aligned}
& \cos (\lambda \nabla)=1-\frac{4 \lambda^{2}}{9} \nabla^{2}+\frac{\lambda^{4}}{63} \nabla^{4} \\
& \sin (\lambda \nabla)=\lambda \nabla-\frac{\lambda^{3}}{9} \nabla^{3}+\frac{\lambda^{5}}{945} \nabla^{5}
\end{aligned}
$$

The details of the numerical method for solving the high order Boussinesq equations could be found in Madsen, Bingham and Liu (2002) for the one dimensional case . In order to compute the fifthderivatives numerically, seven points difference stencil is introduced. For time integration, the fifthorder Cash-Karp-Runge-Kutta scheme is used. Regarding to the numerical method for the horizontal two dimensional model, the combined method of the meshless finite difference method and the least square approximation is used, refer to Wang and Liu (2006). Using the meshless method, complex coastal boundaries are easy to be discretized and local grid refinement is alse easy to be applied. 
After including transient beach variation in Eq. 4, the properties and accuracy of the Boussinesq equations on the transfer function between the beach variation and the free surface elevation are discussed by Zhao, Wang and Liu (2009). For long waves in water especially for tsunami waves, the proposed Boussinesq equations with the operators of Padé series approximation Eq. 6 could provide sufficient accuracy for the transient beach movement. At the same time, the fully nonlinearity and highly dispersive property are retained in the model.

\section{GENERATION OF TSUNAMI WAVES}

The whole life span of a tsunami includes generation from submarine earthquakes or landslides, propagation in open ocean, runup and perhaps breaking during propagation on slope beach. Prediction of tsunamis' generation provides the initial information for the later studies. The motivation of this part is to study the inception of waves near the source of submarine earthquakes, including orders of wavelength and wave height.

We assume the profile of submarine movement expressed as

$$
\eta(x, t)=-2 A C \operatorname{sech}^{2}(C x) \tanh (C x) \sin \left(\frac{\pi t}{2 \tau}\right)
$$

Parameters in Eq. 7 refer to Table 1 in which the scale parameters $L, S$ and $\tau$ are provided by Ward (2002). Fig. 1 shows the profile of M8.5 earthquake. The horizontal scale $L=79 \mathrm{~km}$, vertical displacement $S=5.66 \mathrm{~m}$, period of earthquake $\tau=22.64 \mathrm{~s}$.

The average depth of the Pacific ocean is about $4000 \mathrm{~m}$. We employ this value as the water depth of deep ocean. The water depth of near shore area is assumed to be $800 \mathrm{~m}$. Different magnitudes of earthquake in deep ocean and shallow water are investigated. Waveforms of 5 minutes after the earthquakes are shown in Fig. 2.

When the earthquake magnitude is smaller than M7.5, there are two trains of waves propagating outwards, in which the left going wave train has the leading elevation front and the right going wave train has the leading depression front. When the earthquake magnitude is larger than M8.0, surface displacement is composed by a leading-elevation $\mathrm{N}$-wave (LEN) and a leading-depression $\mathrm{N}$-wave (LDN). It implies that even though the characteristics of the propagation and runup of solitary waves have been studied intensively for understanding coastal harzard due to tsunamis, the evolution and runup of $\mathrm{N}$-waves should be investigated to explain the mechanism of observed phenomena that tsunami waves caused the waterline to first recede before advancing.

Summary of the orders of relative wave height both in deep ocean and shallow water is shown in Table 2. For these general cases, the values of $H / h$ of deep sea tsunamis are less than $10^{-4}$ while the values of $H / h$ of near shore tsunamis are less than $10^{-3}$. The relative wave height of $\mathrm{N}$-waves induced by earthquakes of large magnitude are of the order $O\left(10^{-5}\right) \sim\left(10^{-3}\right)$.

\begin{tabular}{|c|c|c|c|c|c|}
\hline \multicolumn{6}{|c|}{ Table 1. Parameters of submarine earthquakes. } \\
\hline $\mathrm{M}$ & $\mathrm{L}(\mathrm{km})$ & $\mathrm{C}$ & $\mathrm{A}$ & Fault S $(\mathrm{m})$ & Period $\tau(\mathrm{s})$ \\
\hline 6.5 & 8 & 1 & 0.182 & 0.56 & 2.24 \\
7.0 & 14 & 0.5 & 1.3 & 1.0 & 4 \\
7.5 & 25 & 0.27 & 4.27 & 1.78 & 7.12 \\
8.0 & 45 & 0.15 & 13.8 & 3.17 & 12.68 \\
8.5 & 79 & 0.1 & 36.8 & 5.66 & 22.64 \\
9.0 & 141 & 0.05 & 130 & 10 & 40 \\
9.5 & 251 & 0.03 & 385 & 17.8 & 71.2 \\
\hline
\end{tabular}

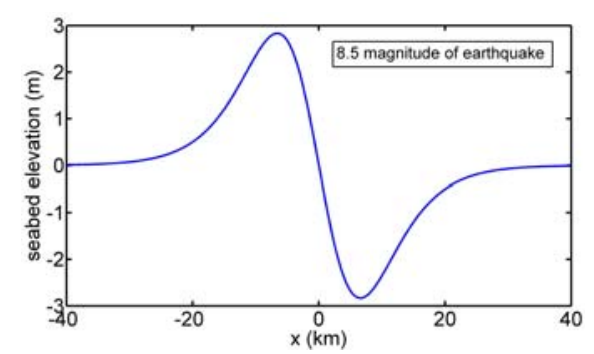

Figure 1. Wave profile of M8.5 submarine earthquake. 

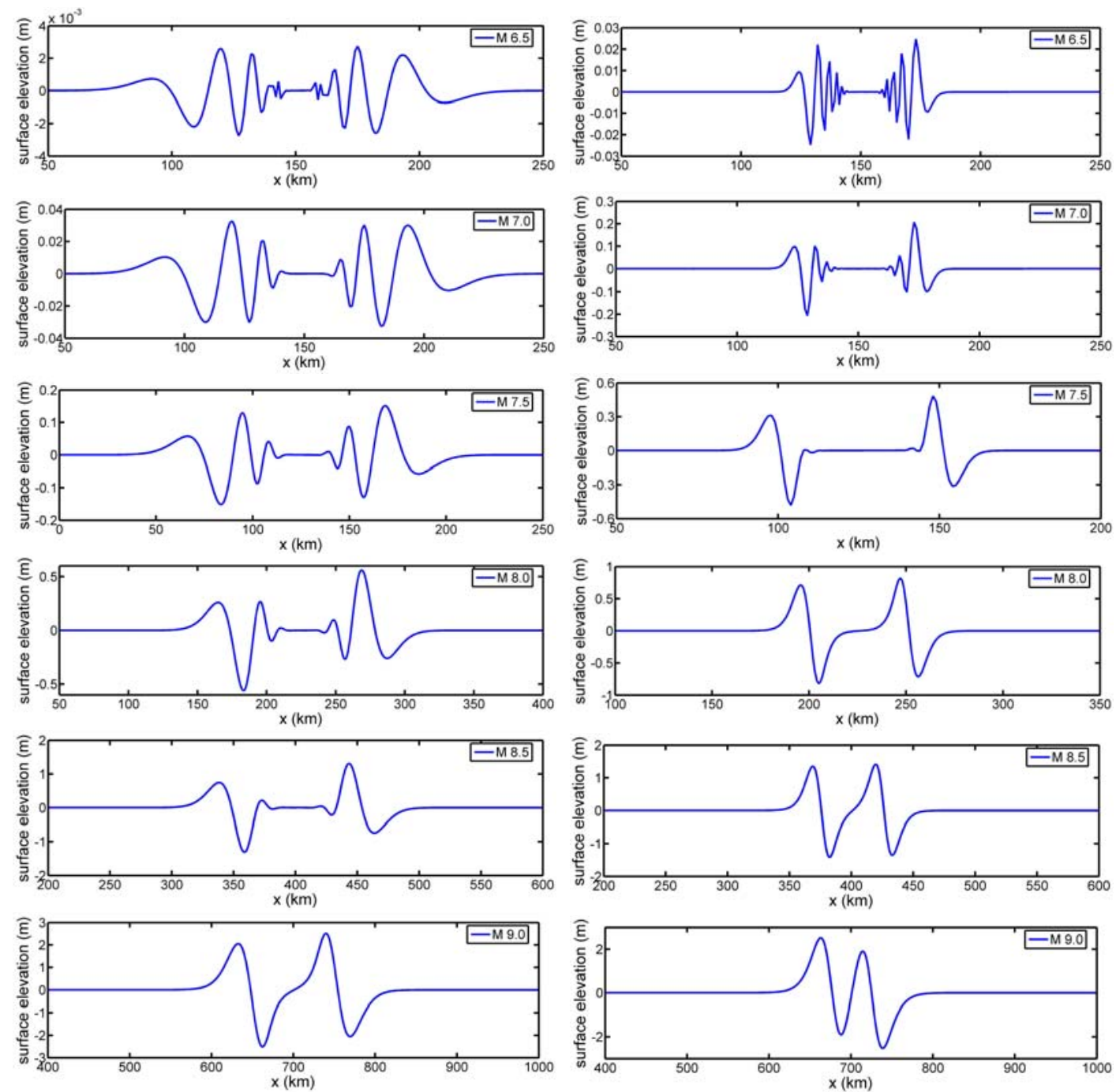

Figure 2. Surface elevation induced by earthquakes of different magnitude. Left column: deep ocean, $h=4000 \mathrm{~m}$, right column: shallow water, $h=800 \mathrm{~m}$.

\begin{tabular}{|c|c|c|c|c|c|c|}
\hline \multicolumn{7}{|c|}{ Table 2. Orders of relative wave height of tsunami waves. } \\
\hline Magnitude & 6.5 & 7.0 & 7.5 & 8.0 & 8.5 & 9.0 \\
\hline $\begin{array}{c}\text { Deep sea earthquake } \\
(h=4000 \mathrm{~m})\end{array}$ & $\boldsymbol{O}\left(10^{-7}\right)$ & $\boldsymbol{O}\left(10^{-6}\right)$ & $\boldsymbol{O}\left(10^{-5}\right)$ & $\boldsymbol{O}\left(10^{-4}\right)$ & $\boldsymbol{O}\left(10^{-4}\right)$ & $\boldsymbol{O}\left(10^{-4}\right)$ \\
$\begin{array}{c}\text { Near shore earthquake } \\
(h=800 \mathrm{~m})\end{array}$ & $\boldsymbol{O}\left(10^{-5}\right)$ & $\boldsymbol{O}\left(10^{-4}\right)$ & $\boldsymbol{O}\left(10^{-4}\right)$ & $\boldsymbol{O}\left(10^{-3}\right)$ & $\boldsymbol{O}\left(10^{-3}\right)$ & $\boldsymbol{O}\left(10^{-3}\right)$ \\
\hline
\end{tabular}

It should be noted that these results are based on the simulations over constant water region during the generation of tsunamis, i.e. a few minutes after occurrence of submarine faults in the open ocean. However, the relative wave height and wave length may change due to the deformation and dispersion during propagating over both constant and uneven bottoms.

\section{PROPAGATION OF N-WAVES WITH CONSTANT WATER DEPTH}

The numerical results in the above section show that the typical bottom motion during an earthquake generates waves of $\mathrm{N}$ shape, which may be considered as a solitary wave with a depressed trough. Tadepalli and Synolakis $(1994,1996)$ proposed a general function as a unified model for near shore and far-field tsunamis. If the crest and trough heights are equal, the LEN propagating along the $\mathrm{x}$ axis can be described as

$$
\zeta(x, 0)=\frac{3 \sqrt{3}}{2} H \operatorname{sech}^{2}\left(k\left(x-x_{1}\right)\right) \tanh \left(k\left(x-x_{1}\right)\right) \quad k=\frac{3}{2 h} \sqrt{\frac{H}{h} \sqrt{\frac{3}{4}}}
$$


Like solitary wave, the profile of this $\mathrm{N}$-wave is highly related to the water depth $h$ and nonlinearity $H / h$. For real tsunamis, waveform is associated with the vertical and horizontal scale of seabed movements basically. Consider M9.0 earthquake in deep ocean for instance, see Fig. 2, wave height is about $2 \mathrm{~m}$ and wavelength is about $100 \mathrm{~km}$. But the wavelength is $800 \mathrm{~km}$ if calculating by Eq. 8 . So there is limitation of using Eq. 8 to simulate tsunami waves. To obtain wave profile as reality, we introduce a parameter $\gamma$ following Tadepalli and Synolakis (1994, 1996), which adjust the length of $\mathrm{N}$-wave. Eq. 8 is modified as:

$$
\zeta(x, 0)=\frac{3 \sqrt{3}}{2} H \operatorname{sech}^{2}\left(k\left(x-x_{1}\right)\right) \tanh \left(k\left(x-x_{1}\right)\right) \quad k=\gamma \frac{3}{2 h} \sqrt{\frac{H}{h} \sqrt{\frac{3}{4}}}
$$

$\mathrm{N}$-waves with different values of $H / h$ propagating 4000depth and 8000depth distance are shown in Fig. 3. For the cases of $H / h \leq 10^{-3}$, it is obtained that the wave profile keeps almost the same as the initial $\mathrm{N}$-waves except the tail of small waves even when it propagates over a long distance, say 8000 water depth. For the case of $H / h=10^{-2}$, there is obvious deformation during the propagation. The strong dispersion causes a wave train. It seems that the leading trough is vanishing slowly. Given the results in the above section, tsunami waves which are generated in deep ocean and shallow area are of the order less than $10^{-3}$. Anyway, $H / h=10^{-2}$ doesn't belong to the real tsunamis' scale range. Therefore, tsunamis induced by submarine faults can generally be considered as non-deformation waves when they propagate in constant water region of global scale in earth.
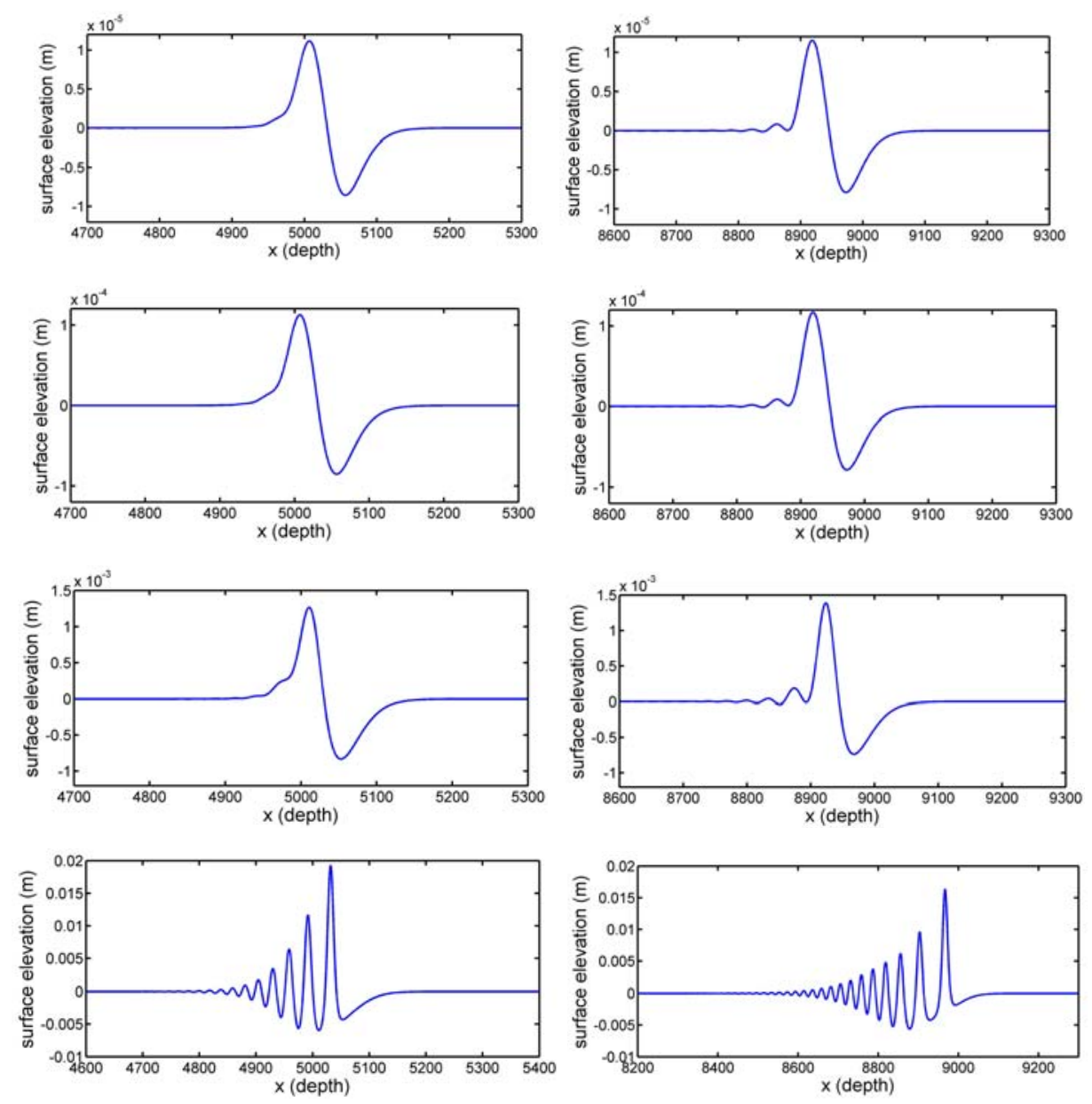

Figure 3. Waveforms of LDNs propagating over a long distance. Relative wave height $H / h=10^{-5}, 10^{-4}, 10^{-3}, 10^{-2}$. Left column: 4000depth, right column: 8000depth.

The relative wave height $H / h$ of tsunami waves in the deep ocean is quite small. But when the wave propagates on the gentle continental shelf, $H / h$ increases significantly. This involves in the wave shoaling and scattering process depending on the beach slope. When an LDN with $H / h=10^{-3}$ shoaling on a very gental slope 1:6000, which is similar to the continental shelf of East China Sea, $H / h$ can be 
magnified to the order of $10^{-1}$, refer to Fig. 4. In this circumstance, the dispersion and nonlinearity effects may coupled together. Therefore, the numerical model should have reasonable capability for modelling both dispersive and nonlinear properties of waves.
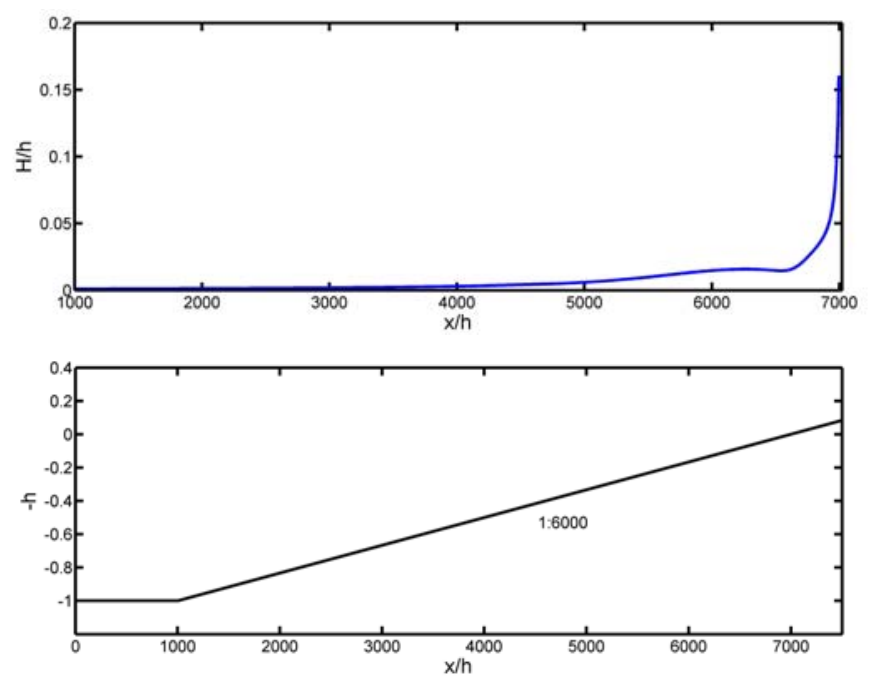

Figure 4. LDN propagates on a long gentle slope beach 1:6000. Above: development of relative amplitude of LDN shoaling on a beach; bottom: setup of the beach.

\section{RUNUP OF TSUNAMI WAVES}

The destruction of coastal area in the tsunami events is caused by runup. Great effort has been made on the study of solitary wave runup in the previous decades. Many useful results have been obtained both by analytical methods and numerical methods, as well as physical model experiments. Comparison between the numerical results of present Boussinesq model and the analytical solution of NSWE for solitary wave runup will be studied firstly.

A flat bottom with a slope beach of angle $\theta$ is setup as shown in Fig. 5. The origin of the coordinate system is at the initial position of shoreline and $x$ axis points to offshore direction, The initial conditions including surface elevation and velocity field are set as follows:

$$
\begin{gathered}
\zeta(x)=H \operatorname{sech}^{2}\left[k\left(x-x_{1}\right)\right] \quad k=\sqrt{\frac{3 H}{4 h^{3}}} \\
u=\sqrt{\frac{g(H+h)}{h} \zeta} \\
c=\sqrt{g(H+h)}
\end{gathered}
$$

where $H$ is wave height, $h$ is water depth, $k$ is wave number, $u$ is horizontal velocity on the free surface, $c$ is solitary wave celerity. $x_{1}$ is the initial location of wave crest. As the wave front is setup at the toe of the slope beach, value of $x_{1}-x_{0}$ equals to the half length of solitary wave. Definition of half length in this paper is that at a distance of $x=L / 2$ away from the crest, the vertical displacement of the free surface is reduced to $5 \%$ of wave height. This gives (Synolakis 1987)

$$
L / 2=\frac{\operatorname{arccosh}(\sqrt{20})}{k}
$$

Insert the parameter $\gamma$ into Eq 10, a single crest without solitary property can be expressed by

$$
\zeta(x)=H \operatorname{sech}^{2}\left[k\left(x-x_{1}\right)\right] \quad k=\gamma \sqrt{\frac{3 H}{4 h^{3}}}
$$


If $\gamma>1$, it is a single crest thinner than a solitary wave. And if $\gamma<1$, it is a single crest fatter than solitary wave. The horizontal scale of large tsunami wave is of the order $O(10 \mathrm{~km}) \sim(100 \mathrm{~km})$ while $H / h$ is of the order $O\left(10^{-5}\right) \sim\left(10^{-3}\right)$, refer to Fig. 2 and Table 2. Madsen and Schäffer (2010) provided the runup of single wave with arbitrary frequency. The maximun runup of a single crest has the value

$$
R=3.043 H \sqrt{k c t_{0}}
$$

where

$$
t_{0}=\frac{x_{0}}{\sqrt{g h}}=\frac{h \cot \theta}{\sqrt{g h}}, \quad c=\sqrt{g(H+h)}
$$

The comparison between the numerical results and the analytical solution is shown in Fig. 6. The left panel shows maximum runup of solitary waves on a slope 1:19.85. Numerical results are compared with analytical solution and experiment data refer to Synolakis (1987). The present numerical results of the Boussinesq model agree with analytical solution of NSWE both of which are larger than the experimental data. It is argued by Synolakis (1987) that this kind of deviation is caused by bottom friction of beach in experiments other than other effects such as dispersion. For large amplitude solitary waves, the runup value predicted by the Boussinesq model tends to be a little smaller than the analytical solution of NSWE. The right panel of Fig. 6 shows maximum runup of single crests on a plane beach of slope 1:20. Numerical results are compared with analytical solution of Eq. 15. The results are all for non-breaking waves. The present numerical model appears to be predicting runup of a solitary wave and a single crest wave quite well.

Maximum runup of a solitary wave is compared with a fatter crest and a thinner crest. Relative wave height of $H / h=0.01$ is chosen. Comparing with a solitary wave, $\gamma=0.42$ and $\gamma=1.69$ are chosen for fatter and thinner crest wave. Initial surface elevation and time series of shoreline movement are shown in Fig. 7. The thinner crest has the largest value of runup. Snapshots of surface elevation of three waves are shown in Fig. 8 . The left panel is at the time before maximum runup $t=27.5 \mathrm{~s}$. The fatter crest has the largest volume of water near the coastal line which increase the hydrostatic pressure. Large hydrostatic pressure leads to large resistance from the slope which restrain the uprush of the wave. Thus, with the same wave height, the fatter wave results in the lower runup. This is proved by the right figure at the time when the thinner wave reach maximum runup.

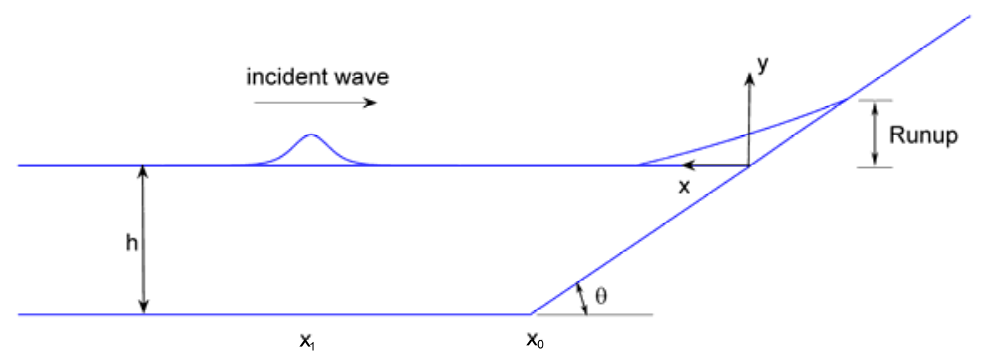

Figure 5. Definition of the plane beach with a slope.
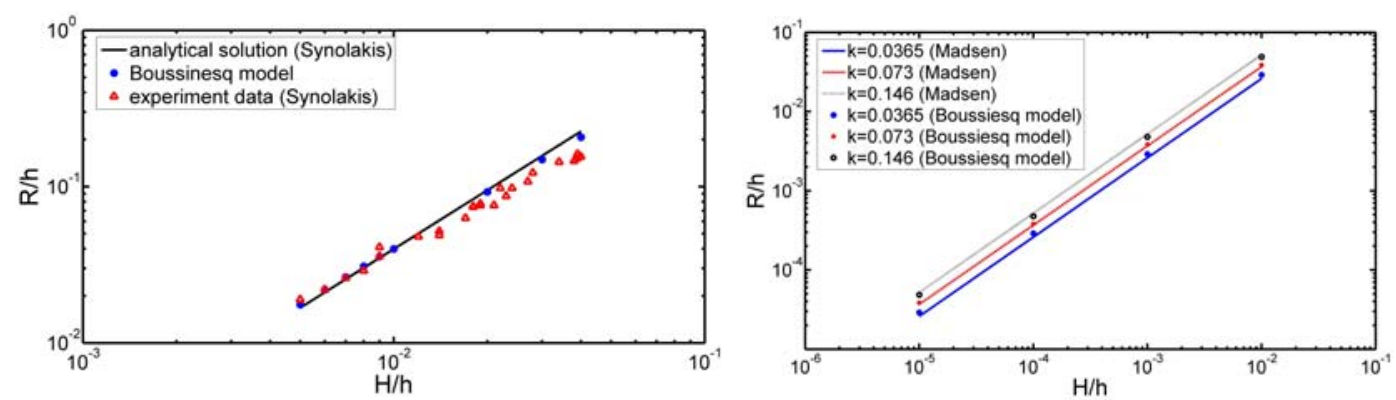

Figure 6. Runup comparison between numerical model and analysis results. Left: Solitary wave. Solid line is analytical solution from Synolakis $(1987), R=2.831(\cot \theta)^{1 / 2}(H / h)^{5 / 4}$, dots are numerical results. Triangles are experiment data. Right: Single crest with tsunami wave scale. Solid line is analytical solution of $k=0.0365$, dash line is analytical solution of $k=0.073$, dot line is analytical solution of $k=0.146$. Stars are numerical results of $k=0.0365$, points are numerical results of $k=0.073$, circles are numerical results of $k=0.146$. 

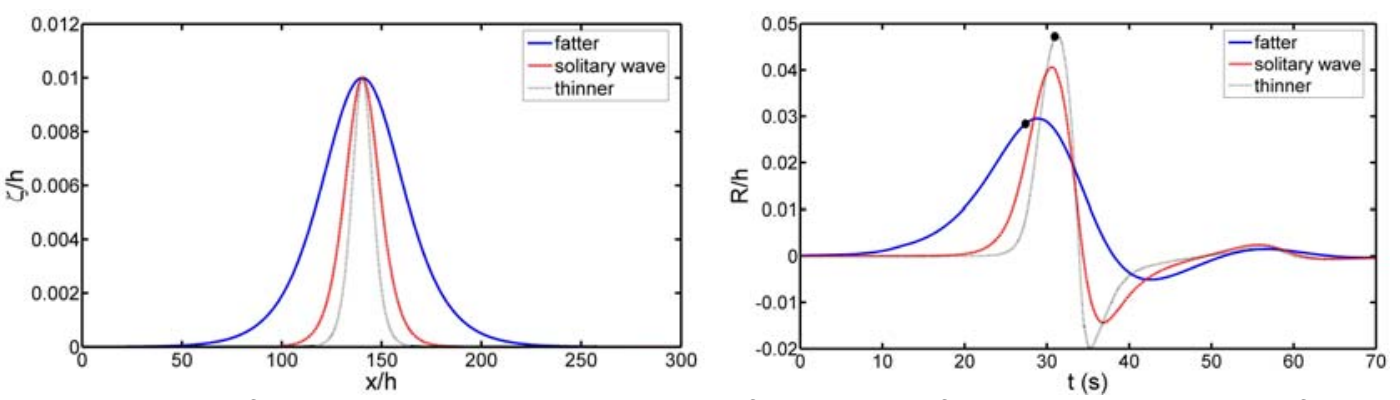

Figure 7. Runup of single waves and solitary wave. Left: Initial waveform. Right: Time series of shoreline movement. The points indicate the time $t=27.5 s$ and $t=31 \mathrm{~s}$.
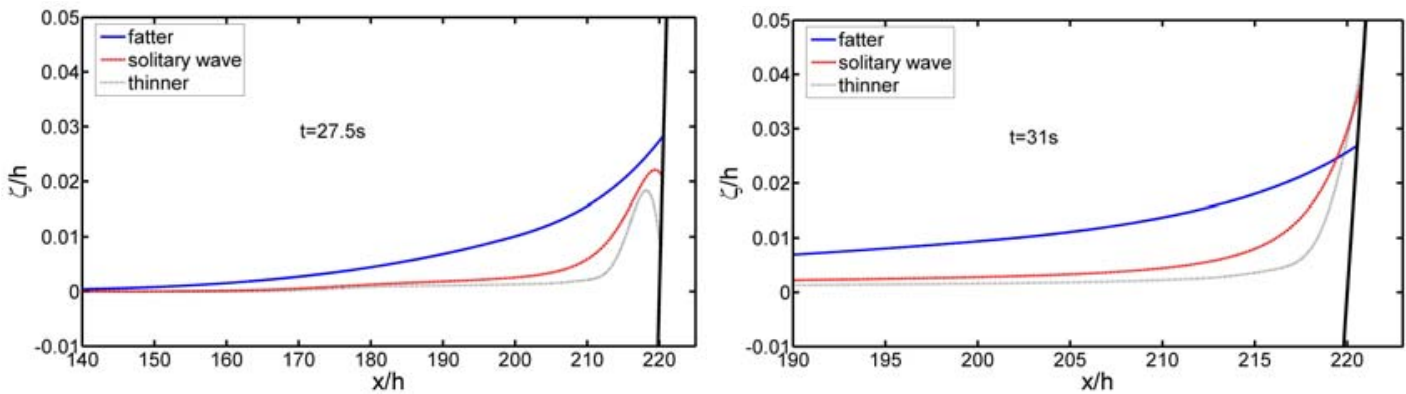

Figure 8. The snapshots of surface elevation during runup. $k=0.0365,0.087,0.146$ for fatter crest, solitary wave and thinner crest, respectively. The toe of slope is located at $x_{0} / h=200$.

Based on the NSWE, Tadepalli and Synolakis (1994, 1996) gave the analytical solution of maximum runup of isosceles LEN:

$$
R=3.86 \sqrt{\cot \theta}\left(\frac{H}{h}\right)^{5 / 4}
$$

Comparison between the numerical results and analytical solution is shown in Fig. 9. The agreement is quantitively good. Similar as the comparison results shown in Fig. 6, under-predicted runup is given by the Boussinesq model comparing with the NSWE for large amplitude N-waves.

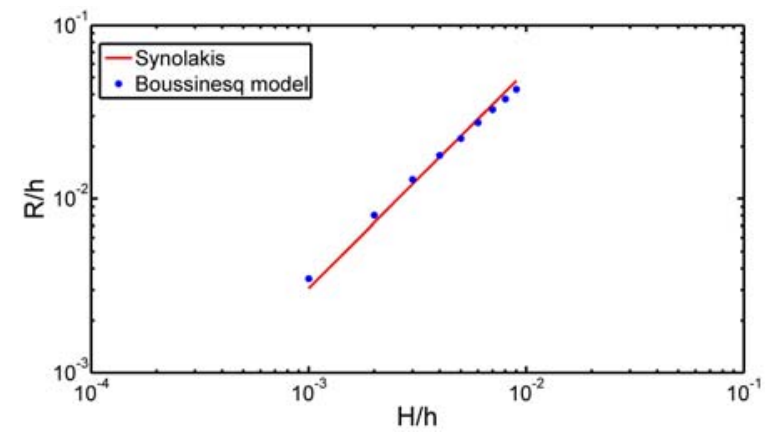

Figure 9. Maxmum runup of LEN on 1:20 slope beach. Solid line is analytical solution of Tadepalli and Synolakis(1994), points are numerical results.

The N-waves, which give a better approximation of tsunami waves, can be described by two counter-acting single waves given by

$$
\zeta(x)=H_{1} \operatorname{sech}^{2}\left[k_{1}\left(x-x_{1}\right)\right]-H_{2} \operatorname{sech}^{2}\left[k_{2}\left(x-x_{2}\right)\right]
$$

where $k_{1}=\gamma_{1} \sqrt{\frac{3 H_{1}}{4 h^{3}}}, \quad k_{2}=\gamma_{2} \sqrt{\frac{3 H_{2}}{4 h^{3}}}$

When $H_{1}=H_{2}$ and $k_{1}=k_{2}$, it is the isosceles $\mathrm{N}$-wave. When isosceles $\mathrm{N}$-wave with a leading depression trough runup on a beach, maximum values of runup and rundown follow (Madsen and Schäffer 2010) 


$$
\begin{aligned}
& \frac{R_{\text {down } 1}}{H \sqrt{k c t_{0}}}=-2.676 \\
& \frac{R_{\text {up }}}{H \sqrt{k c t_{0}}}=4.243 \\
& \frac{R_{\text {down } 2}}{H \sqrt{k c t_{0}}}=-0.712
\end{aligned}
$$

where $t_{0}$ and $c$ are of the same definition in Eq 16 .

Comparison between the numerical results and analytical solution of the NSWE is shown in Fig. 10. For these $\mathrm{N}$-waves with large wave length, the prediction of runup using present model is quite satisfied.
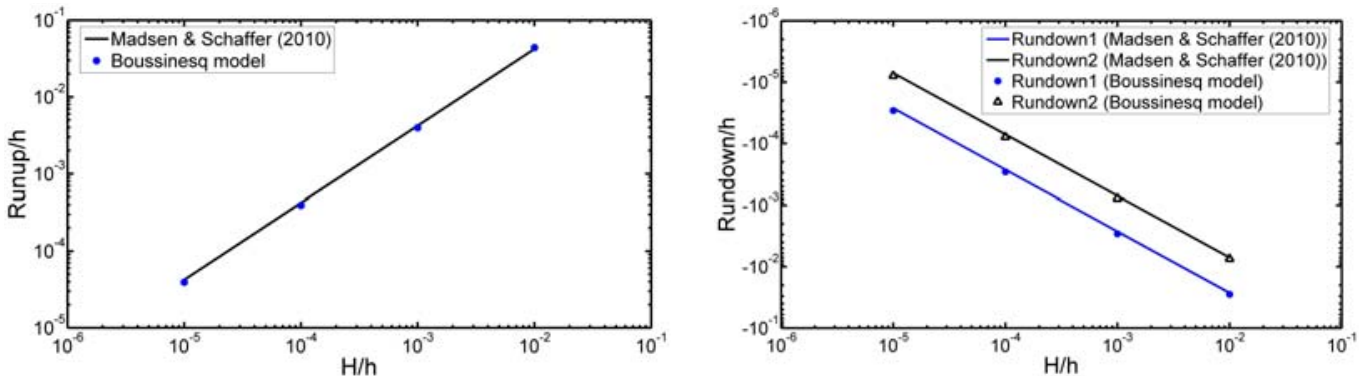

Figure 10. Runup and rundown of LDN on 1:20 slope beach. Solid line is analytical solution of Madsen and Schäffer (2010), points and stars are numerical results.

Then we discuss a solitary wave and $\mathrm{N}$-waves with same crest height propagating on a beach. The left panel of Fig. 11 gives the initial waveform, $H / h=0.005$. For the $N$-wave profile, it is an LEN when propagating to the right direction and an LDN when propagating to the left direction. The time series of shoreline movement are shown in the right panel of Fig. 11. The maximum runup of an N-wave is larger than a solitary wave and LDN leads to larger value than LEN. The wavefront of an N-wave is steeper than a solitary wave which results in larger runup and higher speed of shoreline uprush. Because of the depression trough, there is a significant retreat of shoreline before the maximum runup for LDN.
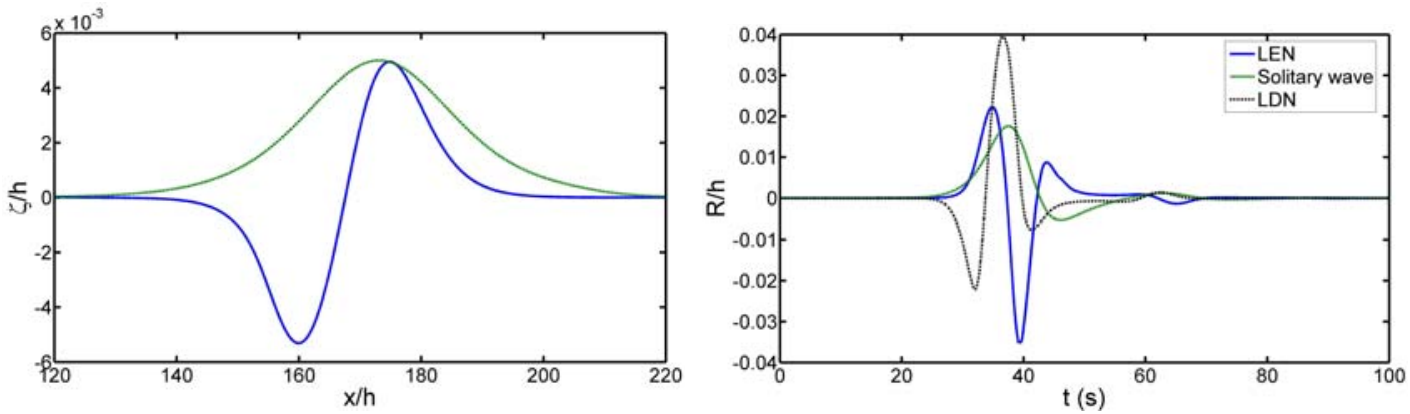

Figure 11. Runup of solitary wave and $\mathrm{N}$-waves with the same crest height. Left: initial waveforms. Right: time series of shoreline movement. Dash line is solitary wave, solid line is LEN, dash-dot line is LDN.

\section{RUNUP OF SOLITARY WAVE ON CONICAL ISLAND}

The conical island experiments provided runup values for validating numerical models and supplemented comparisons with analytical results (Kânoglu and Synolakis 1998). The details of the experiment could be found in Liu et al. (1995). In the two dimensional Boussinesq model, the node-tonode distance is about $0.2 \mathrm{~m}$ at the region far from the island, this mesh is refined around the island and the node-to-node distance is about $0.05 \mathrm{~m}$, as shown in Fig. 12. The time step is $0.02 \mathrm{~s}$ for the simulation. 
The comparison between the numerical results and experimental data are presented in Fig. 13 for the case of an coming solitary wave of 0.1 relative wave height.

The locations of wave gauge could be found in Wang et al. (2006). Comparison between numerical results and experiment data for the time histories of surface elevation at 18 gauges are shown in Fig. 13. From the comparison, both the peak time and the surface elevation give pretty good match, which indicates that the numerical model could accurately predict both the phase celerity and nonlinear effects.

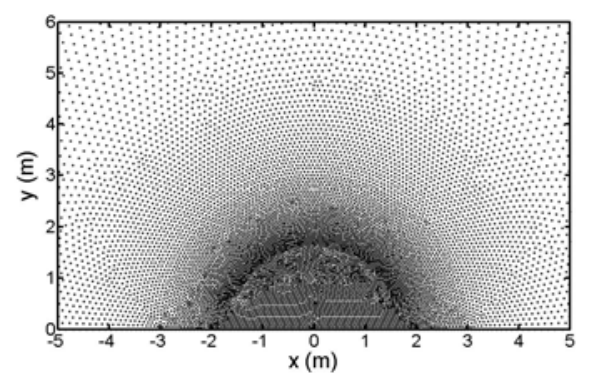

Figure 12. Distribution of the computational nodes around the island.

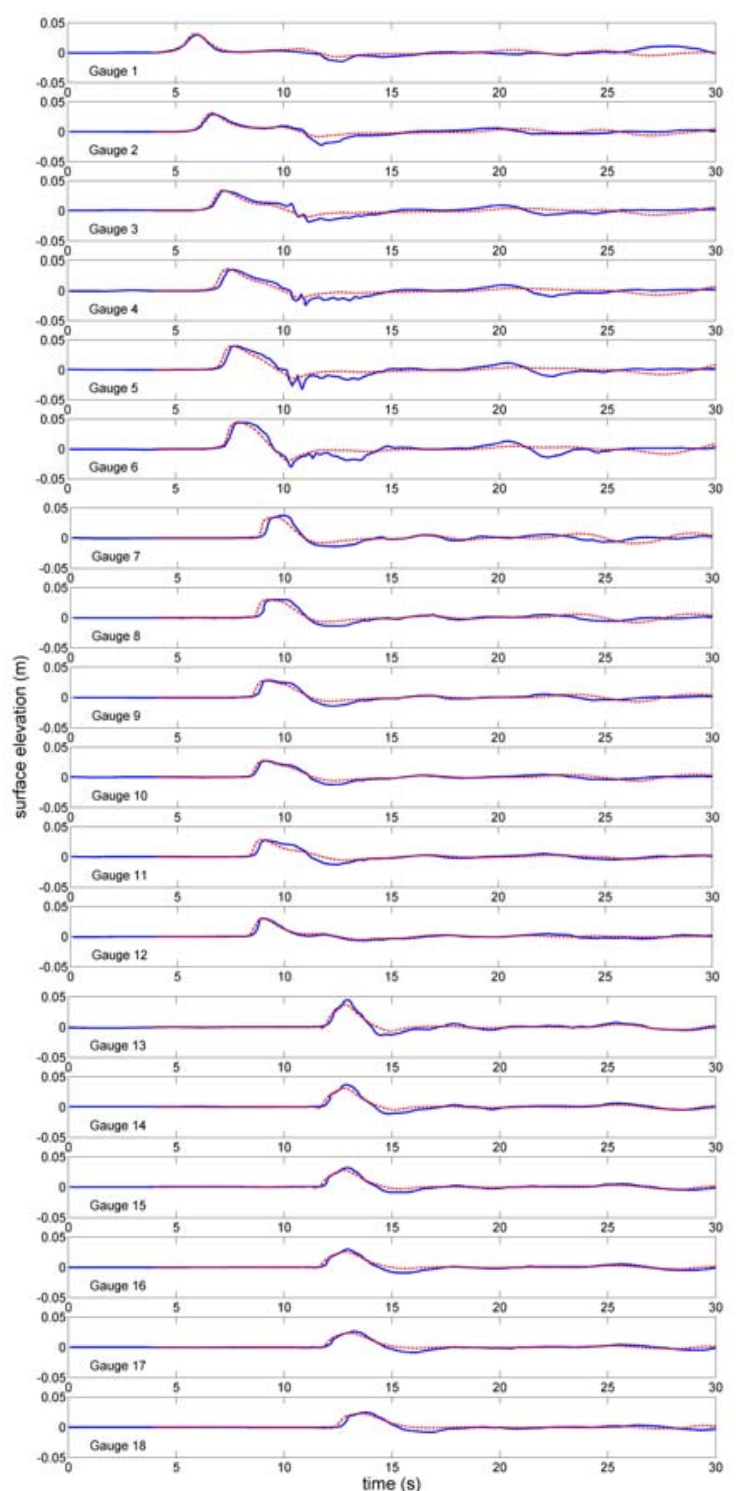

Figure 13. Time histories of the free surface elevations at different wave gauge locations. Solid lines are experimental data and the dash-dot lines are the numerical results with the Boussinesq model. 


\section{NUMERICAL SIMULATION OF INDIAN OCEAN TSUNAMI}

The Indian Ocean tsunami 2004 is simulated using the horizontal two dimensional high order Boussinesq equations. The computational domain and setup of submarine faults are shown in Fig.14. The computational domain is $1017.0 \mathrm{~km} * 1572.5 \mathrm{~km}$. The node-to-node distance is $5 \mathrm{~km}$ in Grid 1 and reduces to $0.5 \mathrm{~km}$ gradually along the coastal line in Grid 2. The total node number is 462346 . Sponge layers are established around the computational domain which absorb the out-going waves. The topography refers to the ETOPO1 which is the data of 1 minute meshes of the earth surface. Faults information takes the parameters in Table 3.

In the submarine earthquake 2004, the seabed ruptures from south to north which last about 450s. In our numerical model, there are three segments along the fault section, shown in Fig. 14. There are 100 seconds delay between fault 2 and fault 1, and 200 seconds delay between fault 3 and fault 2 . The numerical results indicate that tsunami wave hits Sumatra 13min after the earthquake and hits Thailand 2hrs after the earthquake.The free surface elevation at time $7.5 \mathrm{mins}, 13 \mathrm{mins}$, $1 \mathrm{hrs}$ and $2 \mathrm{hrs}$ after the submarine earthquake are shown in Fig. 15.

The locations of tide stations from which the measured water levels are used to validate the numerical results are shown in the left panel of Fig. 16. The locations are Ranong, Kuraburi and the Belgian yacht 'Mercator' anchored about $1.6 \mathrm{~km}$ off the Phuket coast in Thailand. It is demonstrated that the moving waterline on beach has characteristics of an incoming leading-depression $\mathrm{N}$-wave, as both numerical results and field data shown in the right panel of Fig. 16.

Regarding the maximum runup of the tsunami along the coastal area, the computed values of the maximum runup are compared with the observed data from field survey after the Indian Ocean tsunami. Fig. 17 provides the numerical results and observed data of the maximum runup of the coast of Banda Ache. Basically, the computed values of maximum runup of the tsunami in the west coast coincide with the observed data. However, in the north coast, the computed maximum runup is larger than the observed data. The reason is likely to be the location of observation point which are several kilometers apart from the coastal line. Flood moving on land for several kilometers may reduce the consequence runup due to energy dissipation.

It is suggested by Synolakis et al. (2008) that 100-m-grid resolution may be sufficient for fairly plan, wide and long beach, but small offshore and onshore features are likely to affect the runup where more fine resolution is necessary. In this stage, both resolution and bathymetry have not reach that magnitude. Further refinement calculation will be carried out after the relevant data are obtained.

\section{CONCLUSIONS}

A numerical model based on the high order Bousinesq equations is used to study the generation, propagation and runup of tsunamis. A simplified model of the moving bottom is proposed and implemented to simulate the effect of earthquakes of different magnitude. Generally, there are different wave patterns of tsunami near the source for different earthquake magnitude which demonstrates the Nwave profile. Earthquake of large magnitude leads to typical $\mathrm{N}$-wave which can propagate long distance without deformation over constant water region. The maximum runups of the solitary wave, $\mathrm{N}$-wave, single crest and $\mathrm{N}$-wave composed by a single crest and a single trough are confirmed with the analytical solution of NSWE. For solitary wave and N-waves with same crest height, N-waves runup higher than the solitary wave. For the case of Indian Ocean tsunami 2004, the horizontal two dimensional Boussinesq model is used. Computed values of maximum runup of tsunami are validated with the field survey data. 

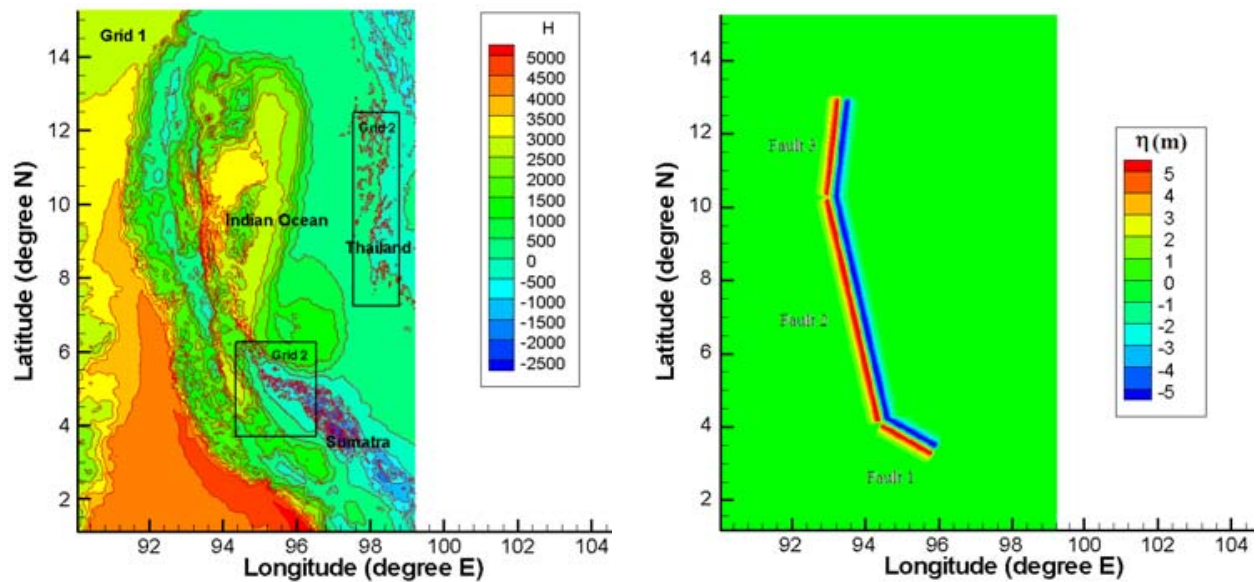

Figure 14. Computational domain and location of the submarine faults.

\begin{tabular}{|c|c|c|c|}
\hline \multicolumn{4}{|c|}{ Table 3. Faults information. } \\
\hline & Fault 1 & Fault 2 & Fault 3 \\
\hline Longitude $\left({ }^{\circ} \mathrm{E}\right)$ & 95.20 & 93.80 & 93.25 \\
Latitude $\left({ }^{\circ} \mathrm{N}\right)$ & 3.80 & 7.25 & 11.65 \\
Length $(\mathrm{km})$ & 200 & 670 & 300 \\
Width $(\mathrm{km})$ & 141 & 141 & 141 \\
Vertical displacement $(m)$ & 10 & 10 & 10 \\
Fault direction $\left(^{\circ}\right)$ & 300 & 345 & 365 \\
Period $(\mathrm{s})$ & 40 & 40 & 40 \\
A (M9.0) & 130 & 130 & 130 \\
C (M9.0) & 0.05 & 0.05 & 0.05 \\
\hline
\end{tabular}
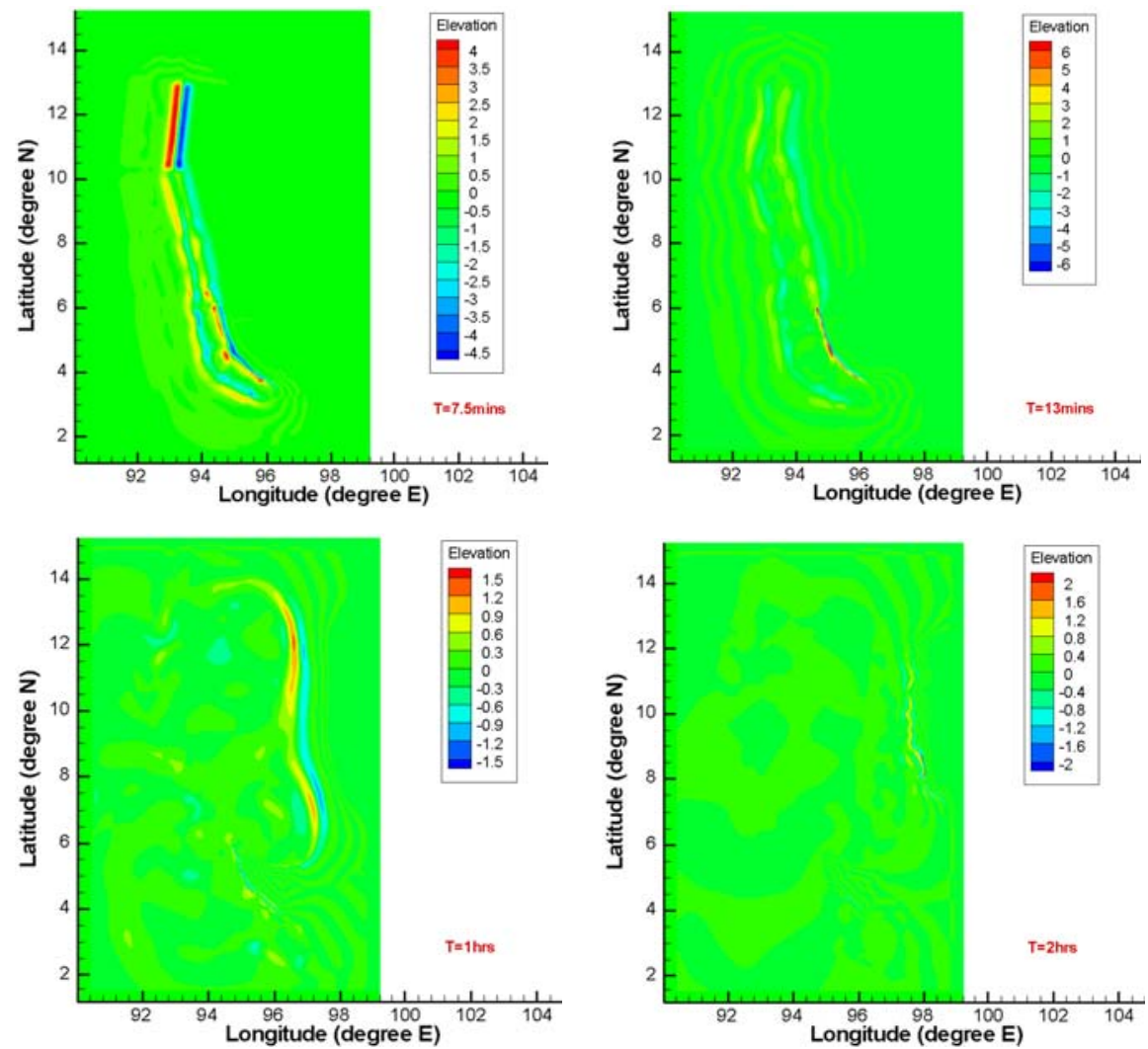

Figure 15. Free surface elevation in the computational domain. 

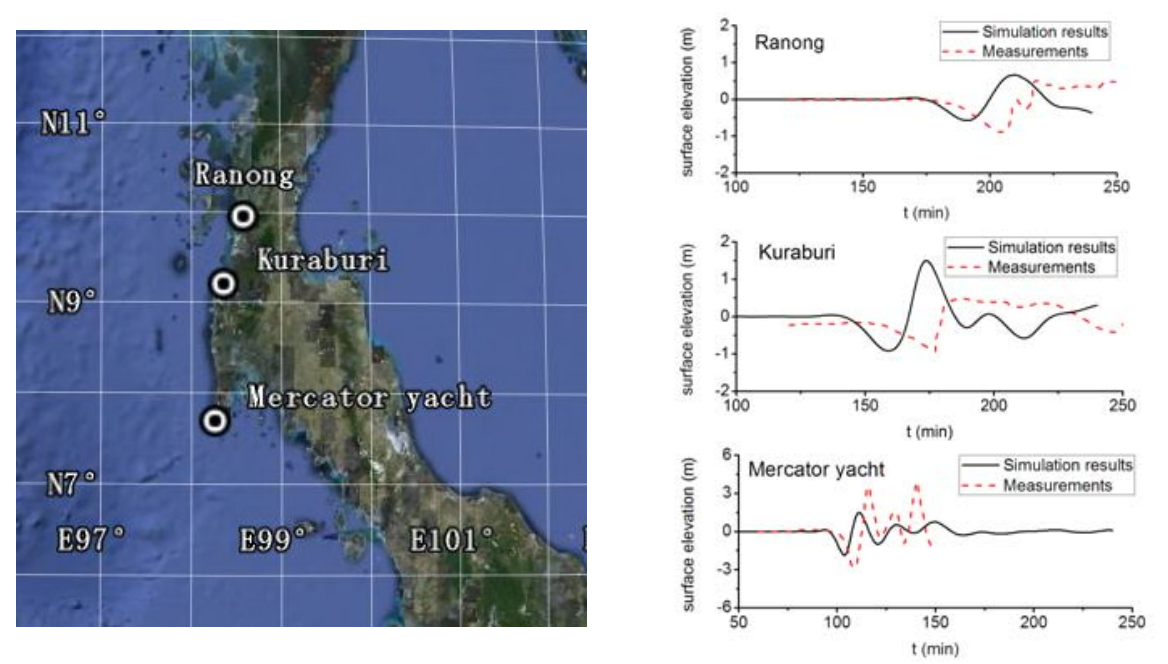

Figure 16. Locations of wave gauge in Thailand and comparison between numerical results and observed surface elevation.
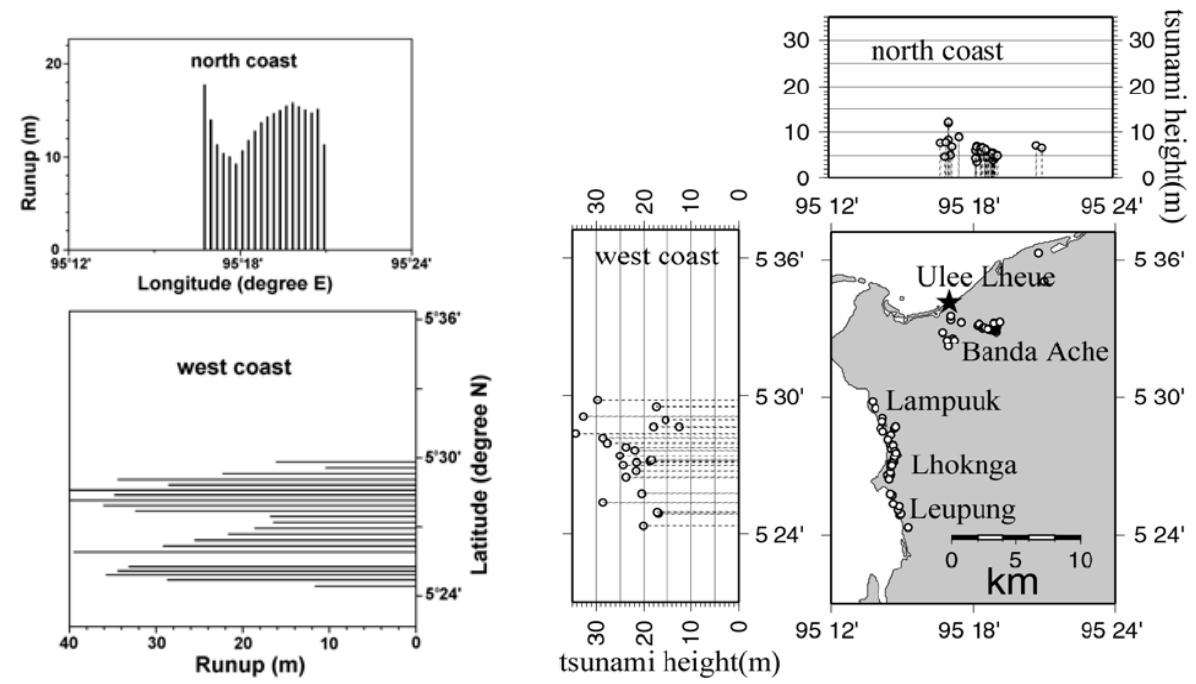

Figure 17. Maximum runup of the Indian Ocean tsunami 2004. Left: numerical result; Right: field survey data (Kawata et al).

\section{ACKNOWLEDGEMENTS}

Special acknowledgements go to Professor Yousheng He at Shanghai Jiao Tong University for his encouragement and inspiring discussion on the research work. This project is supported by the Doctoral Program Foundation of Higher Education of China (20060248046), the National Nature Science Foundation of China (10972138) and Shanghai Leading Academic Discipline Project (B206).

\section{REFERENCES}

Hammack, J. 1973. A note on tsunamis: their generation and propagation in an ocean of uniform depth. J. Fluid Mech., 60, 769 - 799.

Kânoglu, U. and Synolakis, C.E. 1998. Long wave runup on piecewise linear topographies. J. Fluid Mech., 374, 1-28.

Kawata, Y., Tsuji. Y., Sugimoto, Y., Hayashi, H., Matsutomi, H., Okamura, Y., Hayashi, I., Kayane, H., Tanioka , Y., Fujima, K., Imamura, F., Matsuyama, M., Takahashi, T., Maki, N., Koshimura, S., Yasuda, T., Shigihara, Y., Nishimura, Y., Horie, K., Nishi, Y., Yamamoto, H., Fukao, J., Seiko, S., Takakuwa, F. Comprehensive analysis of the damage and its impact on coastal zones by the 
2004 Indian Ocean tsunami disaster. http://www.tsunami.civil.tohoku.ac.jp/sumatra2004/report. html.

Lay, T., Kanamori, H., Ammon, C., Nettles, M., Ward, S., Aster, R., Beck, S., Bilek, S., Brudzinski, M., Bulter, R., DeShon, H., Ekstrom, G., Satake, K., Sipkin, S. 2005. The great Sumatra-Andaman earthquake of 26 December 2004. Science, 308, 1127 - 1133.

Liu, P.L.-F., Cho, Y.S., Briggs, M.J., Kânoglu, U., Synolakis, C.E. 1995. Runup of solitary waves on a circular island. J. Fluid Mech., 302, 259-285.

Madsen, P.A., Bingham, H. and Liu, H. 2002. A new Boussinesq method for fully nonlinear waves from shallow to deep water. J. Fluid Mech., 462, 1-30.

Madsen, P.A. and Schäffer, H.A. 2010. Analytical solution for tsunami runup on a plane beach: single waves, N-waves and transient waves. J. Fluid Mech., 645, 27-57.

Synolakis, C.E. 1987. The runup of solitary waves. J. Fluid Mech., 185, 523-545.

Synolakis, C.E., Bernard, E.N., Titov, V.V., Kânoglu, U., González, F.I. 2008. Validation and verification of tsunami numerical models. Pure appl. Geophys., 165, 2197-2228.

Tadepalli, S. and Synolakis C.E. 1994. The run-up of N-waves on sloping beaches. Proc. R. Soc. Lond. A., 445, 99-112.

Tadepalli, S. and Synolakis C.E. 1996. Model for the leading waves of tsunami. Phys. Rev. Letts., 77, 2141-2144.

Todorovska, M.I., Trifunac, M.D. 2001. Generation of tsunamis by a slowly spreading uplift of the sea floor. Soil Dynamics and Earthquake Engineering, 21, 151-167.

Wang, B.L. and Liu, H. 2006. Solving a fully nonlinear highly dispersive Boussinesq model with mesh-less least square-based finite difference method. Int. J. Numer. Meth. Fluids., 52, 213 - 235.

Wang, B.L., Zhu, Y.Q., Song, Z.P., Liu, H. 2006. Boussinesq-type modeling in surf zone using meshless least-square-based finite difference method. Conference of Global Chinese Scholars on Hydrodynamics, shanghai, China.

Ward, S.N. 2002. Tsunamis. Encyclopedia of Physical Science and Technology, Academic Press.

Witting, J.M. 1984. A united model for the evolution of nonlinear water waves. J Comput Phys., 56, 203-236.

Wu, T.Y. 2001. A unified theory for modeling water waves. Advances in Applied Mechanics, 37, 1-88.

Zakharov, V.E. 1968. Stability of periodic waves of finite amplitude on the surface of a deep fluid. $J$ Appl Mech Tech Phys., 9, 190-194.

Zhao, X., Wang, B.L. and Liu, H. 2009. Modelling the submarine mass failure induced Tsunamis by Boussinesq equations. Journal of Asian Earth Sciences, 36, 47-55. 